\title{
RETROSPECTIVA CRÍTICA DE MIGUEL OTERO SILVA
}

\author{
POR \\ Carlos Pacheco \\ Universidad Simón Bolívar
}

Las dos vertientes de la actividad de Otero Silva confluyen, se unen, se identifican en su creación poética. Miguel pertenece a la gran familia de los poetas testimoniales que han sabido escaparse de sí mismos, trascender de su indispensable confrontación con el alma propia, superar su justo orgullo de creadores de sueños y de mitos, para buscar la comunión de boca a boca con los pueblos, con su innumerable, miserable y admirable semejanza.

Jorge Zalamea

Una mirada crítica de conjunto a la obra de Miguel Otero Silva (1908-1985) debe apoyarse desde un inicio sobre dos constataciones fundamentales. La primera es el reconocimiento de su relevancia como uno de los hombres que marcaron pauta en el siglo veinte venezolano. Y la segunda, la apertura del espectro de la mirada hasta abarcar la diversidad de campos - dentro y fuera de los linderos de lo que llamamos estrictamente "literatura"- que ocuparon su atención. Ambos hechos van unidos, puesto que su influjo sobre nuestra realidad como país fue ejercido desde una multiplicidad de frentes, desde una pluralidad de actividades que —enlazadas todas por una común concepción de principios e ideales-no llegaron a estorbarse entre sí sino que se interpenetraron y se complementaron de continuo en una síntesis muy personal. Es Efraín Subero quien destaca este hecho cuando apunta:

En orden cronológico: poeta, político, periodista, novelista, otra vez poeta, otra vez periodista, empresario, humorista, otra vez político, otra vez novelista, crítico de arte, dramaturgo, viajero de lugares y experiencias, deportista, hasta crítico literario; todo eso ha sido progresivamente, $y$ en ocasiones todo a la vez. Al fin y al cabo no existe un solo Miguel Otero Silva (Subero 1978: 13).

Aunque nuestro interés en este trabajo se centrará en la obra literaria y particularmente en la producción novelística, aquélla que más nítidamente inscribe el nombre de Otero Silva en el registro de la posteridad dento y fuera de Venezuela, no deben pasar desapercibidas sus otras actividades en diversas esferas de la cultura y de la vida pública, 
puesto que en muchos casos, y en virtud de esa unidad de concepciones antes aludida, ellas vendrán a incidir sobre sus perspectivas y su particular manera de escribir.

Estas múltiples facetas comienzan a expresarse desde muy temprano en su vida. Ya en 1924 publica su primer poema. Bajo el seudónimo de "Miotsi"; escribe en Fantoches y Caricaturas, conocidas publicaciones humorísticas de la época; y está presente también entre los colaboradores de válvula, revista señera del vanguardismo venezolano. Antes de terminar esa década y junto a figuras tan relevantes como Rómulo Betancourt, Miguel Acosta Saignes, Jóvito Villalba e Isaac Pardo, entre muchos otros, participa en los célebres sucesos de la "Semana del Estudiante" y en la frustrada insurrección cívico-militar de 1928, fecha que diera nombre a su generación. Una vez exilado, se une a la fracasada expedición que al año siguiente trata de derrocar el régimen gomecista. Finalmente, antes de 1930, comienza la escritura de Fiebre, la que sería su primera novela.

Como puede verse, al filo de los veinte años habían despuntado ya en Otero Silva prácticamente todas las inquietudes que vería desarrollarse a lo largo de su trayectoria posterior. Como político, después de militar en el Partido Comunista entre 1930 y 1951 , mantiene una posición independiente de izquierda que lo lleva al Senado en el primer período democrático posterior a la dictadura perezjimenista. Sin embargo, sus convicciones ideológicas, aunque inalteradas en lo fundamental, encontrarán mejor cauce durante el resto de su vida en la práctica de las diversas modalidades de escritura -el periodismo, el humorismo, la poesía, y sobre todo la ficción novelística- que nuclearán su atención como intelectual y como creador.

La práctica del periodismo en sus diversas facetas es posiblemente la más evidente entre estas labores. Como han expresado varios de sus colegas, Miguel Otero Silva llevaba este oficio en la sangre. No sólo es incapaz de dejar de practicarlo, sino que además admite gustoso que lo periodístico se filtre a sus otras formas de escritura. No debe extrañar por ello, como veremos, que el novelista inicie su trabajo procediendo como reportero de investigación, ni que algunos de sus poemas adquieran la forma de entrevista, de reportaje o de editorial. En el diario El Nacional, que fundara junto con su padre Enrique Otero Vizcarrondo en 1943, desempeña las más variadas funciones, desde copropietario y Jefe de Redacción hasta reportero y redactor de todas las secciones, como lo hace, en alarde de versatilidad, en una de las ediciones aniversarias del periódico.

$\mathrm{Al}$ igual que la actividad periodística, el humorismo está muy cerca de las pasiones y aficiones de Otero. Su contribución, junto a la de Leoncio Martínez (Leo), Francisco Pimentel (Job Pim), o Francisco José "Kotepa" Delgado, entre otros, es fundamental para el desarrollo de este género en Venezuela. Es recordado como el "Mickey" de las "Sinfonías tontas", publicadas hacia 1936 en el diario Ahora, y como fundador y participante principal del sèmanario El Morrocoy Azul (1941) donde, bajo diversos seudónimos, despliega una serie de crónicas sobre sucesos locales (Sherlock Morrow), acontecimientos políticos (Morrocuá Descartes) y eventos deportivos (Morrocoy Sprinter), a la vez que versos humorístico-sentimentales (Lúcido Quelonio). El humorista reaparecerá en secciones fijas de El Nacional bajo las firmas de Martín Fierro y Aureliano Buendía, así como en el libro Las celestiales (1965) y cultivando el remake humorístico del teatro en verso en Don Mendo 71 (remedo de La venganza de Don Mendo, de Muñoz Seca) y en Romeo y Julieta (1975). Dos recopilaciones de su obra humorística fueron publicadas en 1972 y 1979, respectivamente. 
Aunque propiamente la poesía no haya ocupado nunca el centro de su actividad literaria, la vena lírica pervivió a lo largo de toda su vida como escritor, distinguiéndose por la versatilidad en el manejo (a menudo paródico) de técnicas tradicionales y modernas de versificación, y asociada fundamentalmente a los temas que no dejaron de preocuparle hondamente, como la denuncia socio-política, el amor, la amistad y la muerte. Esta vertiente expresiva, estudiada por Fernando Paz Castillo (1975), se manifiesta a lo largo de varias décadas en libros como Agua y cauce (1937), 25 poemas (1942), Elegía coral a Andrés Eloy Blanco (1958) y La mar que es el morir (1965). Un volumen de su Poesía completa fue publicado en 1972.

Comprender la interrelación de estas tres líneas de escritura, a las que habría que sumar una obra ensayística, de sesgo más circunstancial pero nada deleznable, es importante para interpretar su obra de ficción, que ocupará nuestra atención en el resto de este trabajo. En una entrevista realizada en Caracas en 1966, Otero Silva se refería con toda lucidez a este fenómeno de multiplicidad e interpenetración genérica, relacionándolo con su raigal preocupación por el proceso sociocultural venezolano:

Periodismo, humorismo y obra literaria son, en mi caso, tres ingredientes consubstanciales que se han influido mutuamente. Digo consubstanciales porque todas mis otras actividades, incluso las políticas, han sido complementos acarreados por el proceso ambiental venezolano. Si es cierto que los hombres nacen para un destino preconcebido, el mío no fue otro sino el de periodista, humorista y escritor, las tres cosas a un tiempo. Aquí entre nos, ¿no se ha fijado usted en que Fiebre y La muerte de Honorio tienen mucho de reportaje, "El niño campesino" [un poema], de entrevista, "El taladro" [un poema], de editorial y "El galerón del gallo zambo" [versos humorísticos], de crónica deportiva? Como durante mi labor periodística de tantos años, mis crónicas fueron muchas veces escritos de poeta, y mis editoriales o manchetas productos del humorismo (Subero 1978: 41).

Aun aceptando esta visión de interrelación genérica en toda su vasta obra, desde una perspectiva crítica e histórico-literaria como la que funda este trabajo, no hay duda de que es necesario dedicar mayor atención a la ficción novelística, que constituye el aporte fundamental de Otero Silva a la cultura venezolana y latinoamericana.

Las páginas que siguen se proponen entonces, precisamente, realizar un recorrido por esa obra narrativa que deberá, por fuerza, ser más detallado y más explícito. Esta relectura nos permitirá un acercamiento descriptivo, interpretativo, y valorativo capaz de dibujar una imagen más cabal de su novelística, en la secuencia cronológica de sus obras de ficción: Fiebre, en sus dos versiones de 1939 y 1971, Casas muertas (Cm 1955), Oficina $N^{\circ} 1$ $\left(O N^{\circ} 1\right.$ 1960), La muerte de Honorio (LmH 1968), Cuando quiero llorar no lloro (Cqlnl 1970), Lope de Aguirre, Príncipe de la libertad (LAPl 1979) y La piedra que era Cristo (LpeC 1984).

Valiéndose fundamentalmente de un acercamiento diacrónico y comparativo, este periplo intentará establecer las principales constantes temáticas y de procedimiento, resaltar valores de estilo paulatinamente acrisolados, detectar transformaciones nodales de estrategia narrativa, de interés referencial, de perspectiva, así como recurrencias y resonancias que 
apunten hacia ese diálogo - significativo él mismo- entre los diversos componentes de la familia novelística de Miguel Otero. ${ }^{1}$

Como se verá, el recorrido crítico alcanzará a mostrar un tránsito desde un realismo testimonial muy apegado a la inmediatez del suceso reciente venezolano y la experiencia vivida hasta un mayor interés por la novelización de referentes históricos más amplios, a la atención a una determinada figura histórica, y en especial hacia el incremento de una conciencia de la ficcionalidad, revelado en las últimas obras por claras manifestaciones de autorreferencialidad. Aunque teniendo en consideración el corpus novelístico oteriano en su totalidad, las naturales limitaciones de un artículo como éste harán que centremos nuestra atención en las novelas de importancia más señalada.

En efecto, la primera y más obvia de las constataciones de este viaje lectural es la que nos muestra la novelística oteriana como compuesta por dos grandes bloques o ciclos narrativos. El primero de ellos se caracteriza por colocar la atención referencial sobre algunos momentos cruciales del devenir histórico venezolano en este siglo, desde los sucesos políticos de 1928 (Fiebre) hasta el final de la dictadura perezjimenista hacia 1957-1958 $(\mathrm{LmH})$, pasando por la decadencia de la sociedad agraria $(\mathrm{Cm})$ y el surgimiento correlativo de nuevos modos de producción y convivencia social, acarreados por el desarrollo de la explotación petrolera en las décadas del treinta y cuarenta $\left(O N^{\circ} I\right)$.

$\mathrm{Si}$ atendiéramos sólo al aspecto temático, este primer grupo de novelas concluiría con la ficcionalización de los difíciles comienzos de la etapa democrática en los años sesenta, a través de los retratos paralelos y contrastantes de los tres Victorinos en Cqlnl. Sin embargo, a causa de su notable apertura hacia mayores libertades técnicas, de su modernidad en general como estructura novelesca, del marcado tono humorístico que la distingue y de la aparición en ella de unos primeros pero inequívocos rasgos metaficcionales, esta obra merece ser integrada también al segundo ciclo. Podría decirse, en otras palabras, que $C q \operatorname{lnl}$ es una suerte de bisagra o intersección entre los dos ciclos.

El primer grupo podría caracterizarse entonces sobre todo por su interés y su apego referencial a la realidad histórica inmediata. En efecto, en Fiebre predomina la orientación testimonial y autobiográfica. Vidal Rojas, el estudiante rebelde, el guerrillero, el preso político que la protagoniza constituye sin duda una especie de silueta ficcional de la experiencia y las concepciones tempranas del novelista, participante como dijimos de aquella insurrección juvenil del 28, hermosa por su pureza y su arrojo, rayanos en la ingenuidad. En tanto testimonio de vivencia política y personal y también por la carga de denuncia antidictatorial que llena sus páginas, Fiebre se vincula con $\mathrm{LmH}$, novela que se funda en entrevistas con tres presos políticos del perezjimenismo.

El resto de las novelas del grupo manifiesta también una pareja voluntad de realismo narrativo, una preocupación de carácter periodístico por documentar en fuentes auténticas los diversos procesos sociales o eventos particulares construidos por la ficción. Como

\footnotetext{
${ }^{1}$ El presente artículo se funda en el texto de una ponencia titulada "Del realismo testimonial a la novela histórica: trayectoria ficcional de Miguel Otero Silva", presentado en el simposio Venezuela: sociedad y cultura al final del siglo, realizado en la Brown University (Providence, Rhode Island) en noviembre de 1990 y aún inédita.
} 
sistema de trabajo del escritor, una labor indagativa precede y funda el esfuerzo escriturario. El novelista se prepara mediante una indagación bibliográfica y sobre todo a través de una técnica reporteril con visos de trabajo de campo, incluyendo visitas a los lugares donde se ambientará la acción y entrevistas a los protagonistas reales o testigos privilegiados. Intenta lograr así un lenguaje perfectamente adecuado al lugar, la época y la edad de los personajes, así como la máxima precisión en los más pequeños detalles - las plantas, las comidas, las enfermedades, las noticias, los personajes característicos- que el narrador realista tanto anhela y tanto busca.

En un diálogo con estudiantes del Instituto Pedagógico de Caracas efectuado en febrero de 1969, es decir poco después de publicada $L m H$ y ya iniciada la escritura de $C q \operatorname{lnl}$, Otero Silva (1976: 39-58) expresa con bastante claridad su propia apreciación acerca de la obra cumplida hasta el momento, señalando como rasgo principal de su ficción ese esfuerzo de apegarse a la realidad venezolana vivida o presenciada o más bien (tendríamos que decir desde las teorizaciones actuales de los procesos de ficcionalización) de esforzarse por producir en el lector un convincente efecto de realidad a través la elaboración ficcional de datos auténticos, fruto de la vivencia o la investigación. Según expresara entonces:

La concepción de los ambientes es estrictamente venezolana, porque mis novelas son reflejos de una realidad venezolana más o menos vivida o presenciada por el novelista (1976: 41).

Más adelante, (1976: 44-45) insistirá en el carácter autobiográfico de Fiebre, en la presencia de rasgos y personajes auténticos en $C m$ y $O N^{\circ} l$, en la orientación más testimonial y denunciativa de Fiebre y $\mathrm{LmH}$. Además - y esto es lo más interesante para nuestra lectura - revela su modo concreto de prepararse para la labor ficcionalizadora:

Les advierto que realizo para cada novela un trabajo preparatorio de indagaciones y apuntes que me sirve para construir el escenario y dar vida a los personajes ... Para la preparadón de Casas muertas, me fui a Ortiz, que para entonces estaba al borde del derrumbe total, busqué a los sobrevivientes de la época terrible, que eran muy escasos, y ellos me contaron cómo eran en esa época los árboles y los pájaros, qué se comía, cómo se vestían, qué canciones cantaban, y yo comencé a llenar cuadernos con sus confidencias. ... Posteriormente recibí algunas clases o lecciones de Patología Tropical ... Y por último, me encerré a escribir el libro, consultando a cada paso el mamotreto de apuntes que tenía a mano. / En Oficina $N^{\circ} 1$ empleé un procedimiento similar. Me desterré casi un año a la ciudad petrolera de El Tigre ... hablé con quienes tenían mayor número de cosas que contar, visité con ellos los lupanares abandonados, las cantinas derrumbadas, las viejas construcciones descabelladas (1976: 45-46).

Finalmente, en el caso de $\mathrm{LmH}$, revela la necesidad que sintió de basarla sobre los testimonios de víctimas autenticas de las torturas perezjimenistas y revela los nombres de sus "informantes": Eduardo Gallegos Mancera, Luis Miquilena y Salom Meza Espinoza, quienes para ese momento habían hecho ya carrera política en partidos de la izquierda venezolana. Esta confesión resulta sin duda iluminadora porque hace visible la definida concepción que tenía el novelista de entonces no sólo del proceso productivo, sino del sentido mismo de la literatura de ficción. 
La escritura de Fiebre (realizada entre 1931 y 1933, apenas ocurridos los acontecimientos ficcionalizados en ella, y publicada en 1939) muestra sin duda el talento y las dotes del novel narrador. Sin embargo, hasta en su segunda versión, revisada por el experimentado escritor de $1971,{ }^{2}$ impresiona más al lector como testimonio visceral, como deber político-literario cumplido con el país, con sus compañeros estudiantes y consigo mismo, como deuda saldada con la dictadura represora, que como acto estético. El tejido de una historia de amor y un conflicto político donde un héroe puro y simpático ama a una joven perfecta pero imposible y sucumbe a la crueldad de la represión oficial, después de soportar el miedo, la clandestinidad, la experiencia guerrillera y carcelaria, aún hace evocar las propuestas románticas e idealistas de la narrativa del diecinueve.

Desde la perspectiva privilegiada del protagonista, sosias ficcionalizado del escritor, el desarrollo de la historia encarna esa misma interrogante y esa angustia por el sentido y el destino venezolanos que encontramos en José Rafael Pocaterra, en Rómulo Gallegos, en Ramón Díaz Sánchez, en Mariano Picón Salas, en Mario Briceño Iragorri, en Enrique Bernardo Núñez, en Antonio Arráiz, en Arturo Uslar Pietri, como marca de las generaciones intelectuales que - particularmente desde el ensayo y la novela - presidieron nuestra vida cultural en primera mitad de este siglo.

Esa pregunta por la dirección de nuestro derrotero histórico como país, por el sentido y la fisonomía particular de la cultura venezolana, por las causas y remedios de nuestros males sociales, continuará repitiéndose con diferentes ecos a lo largo de toda la novelística de ese momento. Pero en Fiebre, bajo la forma de una propuesta nacionalista, denunciativa y crítica ante el autoritarismo, esa inquietud resulta aún demasiado directa y estridente, programática en exceso. La carta legada por Rojas a sus compañeros en las últimas páginas de la obra (1971: 242-46) es un buen ejemplo de este tono y resuena sin duda para cualquier lector contemporáneo como abierta proclama política injertada en el tronco ficcional:

El futuro es arrancar la patria de las gavetas de los mercaderes y junto a nosotros respira la fuerza que ha de realizar ese porvenir. Respiran centenares de miles de desheredados que se mueren de miseria y de olvido en las ciudades y en los campos. Nuestro puesto está en el seno de ellos porque en sus pechos palpita la sed de justicia (1971: 245).

Esa definida orientación hacia el realismo narrativo de la opera prima prosigue, poetizándose, en $\mathrm{Cm}$ y se diversifca en $O N^{\circ} \mathrm{l}$. La decisión de retomar el camino del novelista a casi veinte años de terminada la novela inicial es importante, porque quien lo emprende es ahora un intelectual maduro, fogueado en el ejercicio del periodismo y trabajado por viajes, lecturas y experiencias políticas y personales.

A pesar de los años que separan su escritura, estas dos novelas deben considerarse unidas, como un díptico narrativo, porque formaron parte en un comienzo de un único

\footnotetext{
${ }^{2}$ Un cotejo ceñido de las dos versiones de Fiebre conduce a Nelson Osorio (1993) a distinguir nítidamente estas versiones como dos novelas diferentes. En un trabajo basado en una conferencia de 1985, pero sólo publicado recientemente, Osorio establece también la división de la obra de Miguel Otero Silva en dos grandes ciclos como los que se señalan en nuestro trabajo, pero ubica la primera versión de Fiebre en el primero, mientras desplaza al segundo la versión de 1971.
} 
proyecto, que terminó desdoblándose en dos relatos (Araujo 1988: 137-138) y porque vinculadas por la línea biográfica de Carmen Rosa Villena, uno de los personajes más logrados de la narrativa venezolana- ellas contrastan a la vez que dialogan y se explican mutuamente.

Estas dos novelas representan la ficcionalización de un cambio histórico fundamental en la vida del país: el tránsito social, cultural, económico, político, del país agrario al país petrolero. Si en Fiebre los valores de la construcción novelesca y el trabajo de estilo están como al servicio del testimonio casi autobiográfico, de la idea, de lo representado, en las dos novelas siguientes, que se mantienen dentro de la dirección realista, el poeta se impone al activista escritor. Se observa en ellas entonces un mayor cuidado de la forma y un deleitarse del escritor en el arte de narrar.

El contraste de una a la otra es un importante elemento enriquecedor del sentido. Este contraste reside en primer lugar en las historias mismas: $\mathrm{Cm}$ relata la nostalgia del perdido esplendor y sobre todo la agonía de un pueblo que ya perdió su razón de ser. $O N^{\circ} l$ cuenta en cambio el surgimiento de otro, de las "casas mal nacidas" de un campamento petrolero que antes de que nadie tenga tiempo de advertirlo se va transformando en una nueva (y muy desordenada) ciudad.

Esta doble orientación hacia el pasado perdido y hacia el futuro vislumbrado y temido coincide con otra oposición - esta vez en cuanto a la perspectiva de la narración- que podría formularse como la de espacios y perspectivas endógenas (en el caso de $\mathrm{Cm}$ ) y exógenas (en el de $O N^{\circ} 1$ ). En efecto, como lo mostrara magníficamente Fernando Aínsa (1972), el pueblo de Ortiz es "un pequeño mundo cerrado y autónomo", donde el paso de los estudiantes rumbo al campamento de trabajo forzado es percibido como una ventolera de verano, que pasa sorpresiva, inexplicada para los que nada saben de los acontecimientos de Caracas. El mundo provisional y desordenado del campamento petrolero, en contraste, aparece como un hervidero de personajes de orígenes, costumbres e intereses disímiles que confluyen allí atraídos por la ilusión de una riqueza fácil. La prensa y la radiofonía se encargan de comunicarlos no sólo con el país, sino con el mundo que atraviesa su segunda guerra generalizada.

El contraste se manifiesta también naturalmente en los aspectos formales, ya que $\mathrm{Cm}$ representa un logro estético como manifestación de un regionalismo depurado y poetizado, mientras $O N^{\circ} 1$ significa, incluso desde su estructura narrativa de enfoques rápidos y múltiples sobre los diversos personajes, desde su ruptura de la línea narrativa para incorporar discursos mentales o transcripciones de reportes noticiosos radiofónicos, un primer paso de la narrativa oteriana hacia la experimentación. Esta línea de búsqueda de una mayor libertad en la estructuración del relato y en la escritura misma se encontrará también aunque todavía muy tímidamente- en $L m H$, y con mucha mayor convicción y atrevimiento, casi con desparpajo en algunos momentos, en Cqlnl.

Aunque cada una representa una exploración particular bien diferenciada dentro de la narrativa de Otero, las tres novelas finales pueden identificarse como pertenecientes a una segunda etapa en esa trayectoria. Como expresamos ya, Cqlnl está aún magnetizada por la circunstancia histórico-social inmediata. Las dos restantes novelas en cambio se separarán drásticamente de ella. 
$\mathrm{Al}$ abordar la novela propiamente histórica en la ficcionalización de la gesta de Lope de Aguirre, Otero Silva esta situando su acción narrativa en el siglo XVI y en un espacio ficcional mucho más vasto y diversificado, que se inicia en las provincias vascongadas y avanza, de acuerdo a la trayectoria biográfica del protagonista, por extensos territorios de lo que hoy son Panamá, Perú, Brasil y Venezuela. Su última novela, a su vez, representa una recreación artística de la vida de Jesús al modo como lo realizaron Pasolini, Zeffirelli, o Scorcese en el cine, o Papini y Kazantzakis en la literatura. La distancia referencial del medio sociocultural venezolano es allí todavía mayor, aunque esto no necesariamente desvincule por completo esta novela final de Otero Silva de nuestra problemática más inmediata y más intensamente sentida. Pero, continuemos nuestro itinerario, acercándonos a cada una de estas novelas.

Suele afirmarse que la concepción narrativa y la escritura de $C q \ln l$ significa un viraje fundamental en la trayectoria ficcional del Miguel Otero Silva. En el diálogo con estudiantes que mencionábamos páginas atrás, el escritor muestra por su parte una clara conciencia de la trascendencia de este cambio y del riesgo que él implicaba para su ya bien establecido prestigio como narrador:

Analizando el panorama retrospectivamente, más como lector que como autor, observo una evolución gradual de mi técnica que va de Fiebre a Casas muertas, de Casas muertas a Oficina $N^{\circ} 1$ y de Oficina $N^{\circ} 1$ a La muerte de Honorio, transformación que se intensificará violentamente (se lo anuncio) si logro concluir la novela Cuando quiero llorar no lloro que he comenzado recientemente (1976: 51-52).

Madurada a lo largo de la década de los años sesenta, esta novela aparece como inevitablemente vinculada al difícil proceso de estabilización democrática vivido en Venezuela en ese lapso y como deudora irrenunciable - aunque fuera desde la perspectiva del observador atento- del espíritu contestatario que ventea por esos años de la guerrilla latinoamericana y el movimiento hippie, de la matanza de Tlatelolco en México y los sucesos de mayo en París ese mismo año de 1968.

Respecto de la novelística oteriana anterior, la ruptura marcada por Cqlnl exhibe múltiples facetas. Temáticamente, la obra manifiesta una clara intención de novelar el presente inmediato, radiografiándolo a través de la alternancia contrastiva de los tres protagonistas. Aunque tomando pie en algunas ideas constructivas utilizadas ya en $\mathrm{LmH}$, esta estrategia de paralelismo adquiere aquí una mayor eficacia semántica, al superponer -en llamativa sincronía - similares momentos clave (el nacimiento, la experiencia infantil, el sexo temprano, la violencia y sobre todo la muerte repentina a los dieciocho años) en la vida de los tres protagonistas homónimos, marcados por su adscripción respectiva a un sector de clase determinado: Victorino Peralta, el malcriado niño-bien; Victorino Perdomo, universitario y guerrillero urbano, y Victorino Pérez, el marginal, el hampón, el prófugo.

Este esqueleto estructural de tres líneas accionales centradas en los tres Victorinos y entrelazadas a lo largo del relato permite la gradual construcción ficcional de los tres "mundos" respectivos, alcanzando así una imagen panorámica indudablemente más amplia y compleja (aunque todavía algo esquemática por momentos) de la sociedad venezolana de la época. Como en las obras anteriores tal esfuerzo representacional se funda sobre una 
indagación previa de los rasgos de comportamiento y de lenguaje (especialmente del habla característica del estrato juvenil) dentro de cada sector social ficcionalizado.

El tono de la novela, por otra parte, es llamativamente más liviano. Con $\mathrm{LmH}$, Otero Silva pareciera haberse deslastrado definitivamente de lo que en ocasiones pudiera resentirse como el cumplimiento - dentro de la obra literaria - de un deber político. Esta mayor apertura a lo imaginario, a lo lúdico, a lo propiamente ficcional, no implica en absoluto la renuncia a una línea de pensamiento y a una convicción ideológica que lo acompañarán siempre. Pero se trata sin duda de un distinto enfoque del acto narrativo que - más desapegado del esfuerzo testimonial y reivindicativo- acepta el contar literario como convención y acuerdo jubiloso (el llamado "contrato de lectura") entre el autor y el lector. Este acto de confianza y cooperación, esta suerte de guiño de ojo cómplice que subyace al texto desde sus primeras páginas (y que a veces se hace explícito) libera posibilidades nuevas. Desde la misma selección léxica y organización sintáctica hasta la flexibilización de toda la estructura narrativa, esta nueva comprensión del acto de narrar otorga al texto una mayor frescura y deja paso a un inédito y fructífero cultivo del humor.

Todos estos rasgos posicionan a Cqlnl como la obra que rompe con la concepción realista que abrigaba toda la obra anterior. Se rasga así el velo de la ilusión representativa. El contrato de lectura se hace explícito, desnuda su índole convencional. En la práctica de sus oficios respectivos, emisor y receptor firman un pacto lúdico, el del reconocimiento del texto narrativo como mediación ficcional que construye un referente. Esa imagen ficcional puede resultar más o menos reconocible para uno o para otro, más o menos vinculable con su experiencia, pero - estará ahora claro desde el texto mismo- sólo en tanto constructo simbólico capaz de articular un sistema coherente de impresiones de realidad.

Y una marca patente en el texto de esta conciencia compartida de ficcionalidad es la recurrente amputación de la frase, el abandono repentino de un hilo discursivo que queda en suspenso, detenido, inconcluso. Porque, una vez obtenida la impresión, logrado el efecto, ese hilo lingüístico y narrativo puede cortarse, suspenderse, no sólo sin dañar el proyecto ficcional en desarrollo, sino contribuyendo más bien a asentarlo adecuadamente sobre el principio de ficcionalidad.

No es extraño entonces que este distanciamiento de la intención realista venga aparejado en $C q \operatorname{lnl}$ a la aparición (aún tímida por cierto) de formulaciones metaficcionales, como aquélla donde el narrador llama la atención sobre la distancia entre la represión policial documentada por la prensa y su imagen ficcionalmente reelaborada (1970: 181-182); o esa otra, presente en el excurso también inconcluso, truncado, donde el "novelista" (como se autodenomina el autor allí por primera vez) coloca el foco sobre sí mismo, enfatizando su distanciamiento respecto de los personajes representados:

He aquí el primer arrebato de Victorino Pérez descrito por un novelista que llama "cannabis sativa" a la hierba (en vez de llamarla en orden alfabético: chicharra, chucho, gamelote, grifa, grita, juanita, macolla, machiche, mafafa, ... tabaco, todo, trabuco, tronadora, vaina, vano, varet o yerba), el novelista la llama cannabis sativa, o kif, o hachish, pura literatura, y apenas conoce de sus efectos lo que leyó en un folleto de toxicología (1970: 138). 
Tampoco es extraño que - siguiendo las pautas de su inclinación del momento y de su recién hallada libertad ficcional, Otero realice (en el "Prólogo Cristiano con abominables interrupciones de un emperador romano" que introduce la novela) una primera incursión en la ficcionalización histórica. La liviana irreverencia del humorista establece allí un clima lúdico y una fluida relación con el lector donde - con aires de comedia, de farsase transita naturalmente desde el martirio de San Victorino, a comienzos del siglo IV de nuestra era, al nacimiento de los tres Victorinos venezolanos, el 8 de noviembre de 1948. Allí las condiciones estan dadas ya para la escritura de la novela cimera.

Gestada a partir de uno de los personajes históricos más polémicos y por ello sin duda más biografiados y novelados de la historia americana, $L A P l$ es la mayor contribución de Otero Silva al arte narrativo continental. Novela de madurez, acrisola la sabiduría de un conocedor del oficio y se destaca no sólo por el fino trabajo de reconstrucción de época (y de manera especial del lenguaje del siglo XVI, como muestran sobre todo las numerosas arengas, cartas y proclamas del tirano), sino también por el notable proceso de elaboración ficcional del protagonista y por la amplia gama de recursos compositivos y modalidades de estructuración textual allí utilizados.

Vigoroso y conflictivo, cobrando cada vez mayor autonomía y vida propia, el protagonista magnetiza en efecto, desde un comienzo, la atención del lector. La reiteración de un conjunto de motivos (la estatura pequeña, la tenacidad rayana en tozudez, el control sobre los propios apetitos y el juicio severísimo sobre los desenfrenos de otros, su sentido del destino, la obsesiva relación paterno-filial, su impulso rebelde y su rechazo visceral a la injusticia en cualquiera de sus formas) va estableciendo, de manera paciente y mesurada pero sólida y convincente, las peculiaridades de la contextura fisica, la fisonomía espiritual y la idiosincrasia de este personaje mayor de la ficción latinoamericana.

Varias estrategias de elaboración textual destacan en esta novela: la efectiva alternancia de perspectivas y narradores en primera, segunda y tercera personas; la estructuración de capítulos enteros sobre una polifónica sucesión de voces y textos de variable y conflictiva orientación; la modalización discursiva de ciertos fragmentos como cartas, poemas en prosa, o escenas de tragedia clásica, en un alarde de flexibilidad y solvencia técnica capaz de abrir el texto a la intertextualidad multidiscursiva sin que pierda su impulso netamente novelístico. Un examen siquiera sucinto de esta gran variedad de recursos resulta aquí imposible. Los pasos finales de este recorrido estarán dirigidos más bien a la proposición de aquellas peculiaridades de $L A P l$ que al tiempo definen su personalidad propia y la insertan dentro del proyecto narrativo global de Miguel Otero Silva.

El desplazamiento del foco de atención referencial desde los episodios de la Venezuela contemporánea hasta la figura de Lope de Aguirre en el entorno de la América colonial es, por supuesto, la transformación más obvia. Esta modificación temática no altera substancialmente sin embargo el modo oteriano particular de trabajo como investigador/escritor, su afán por lograr (mediante la elaboración escrituraria fundada en acuciosa indagación previa) el máximo efecto de autenticidad en la realidad representada, así como una propuesta ideológica característica de toda su novelística que podría calificarse en general de popular, democrática y antiautoritaria. 
Lo que sí puede verse mucho más acentuado en $L A P l$ - a partir de lo ya encontrado en $C q \ln l$ - es la conciencia del relato como hecho de ficción, conciencia que se traduce en una mayor libertad estética y en una interacción intensa con un lector más activo, un lector a quien se le exige un mayor esfuerzo de participación; conciencia que se manifiesta también en la aparición de referencias metaficcionales más explícitas y elocuentes. Todo ello, podría decirse, corresponde a un texto más moderno, a una obra más abierta.

En una extensa nota a pie de página (1980: 249-53) que aparece ya bien avanzada la obra, el "novelista" (así vuelve a llamarse el autor a sí mismo en este caso) da cuenta detallada del proceso creativo particular seguido en la producción de esta obra, del carácter únicamente documental de su indagación previa (en contraste con la investigación de tipo reportaje o "trabajo de campo" que ha preferido con anterioridad), y de su inconformidad con la injusta evaluación acerca del personaje histórico hecha por la mayoría de los 188 autores consultados (y citados allí abundantemente). Vale la pena observar algunas muestras de esta importante y extensa nota ya que toda ella - sin abandonar el dejo irónico que caracteriza el tono oteriano de la producción última - constituye una verdadera reflexión del texto novelístico sobre su propio sentido y su proceso constructivo:

1. El novelista, que ha escrito todos sus libros anteriores nutriéndose de experiencias propias y testimonios ajenos, se vio enfrentado en esta oportunidad a un obstáculo cuasi insalvable: no existía sobre la faz de la tierra un solo sobreviviente del siglo XVI a quien interrogar. El novelista se sometió a la humillación de husmear en bibliotecas y archivos, a contrapelo de sus técnicas de trabajo y de sus propensiones personales. Acerca de este infortunado Lope de Aguirre, a quien el novelista eligió como protagonista de su historia, se han escrito centenares de volúmenes que fue imprescindible leer, analizar y acotar. Con hasta entonces desconocida paciencia, el novelista consultó las obras de 188 autores diferentes ... No aparece al final de este libro la lista completa de sus 188 antecesores porque es precepto universal que los novelistas no estamos obligados a rendir cuentas a nadie de nuestras bibliografias. / Lo que sí desea el novelista poner de relieve es la implacable inquina con que casi la totalidad de esos escritores consultados han tratado en sus páginas al caudillo marañón (1980: 249-50).

Como puede verse en el extracto citado, la ilusión representativa se hace aquí patente, se exhibe voluntariamente en tanto ficción, sin el "disimulo" que suele caracterizar a la obra realista. El "novelista" defiende sus fueros, diferentes de los del historiador o los del sociólogo, y se comunica también con su lector de manera "directa" en un reconocimiento indubitable de la vigencia de ese "contrato de lectura" que los vincula, tanto más sólido cuanto más se reconozca la fragilidad, el carácter fingido e ilusorio de la realidad representada y la índole convencional de los recursos utilizados para su representación. Este proceso de incremento de la conciencia ficcional que vimos iniciarse en Cqlnl y desarrollarse al máximo en $\mathrm{LAPl}$, con consecuencias apreciables en el texto narrativo, persistirá en $L p e C$, en tanto esta novela final se plantea desde un principio como válido ejercicio de relectura artística del tan conocido relato evangélico.

La nota citada es también importante por lo que hay en ella de revisionismo histórico, de intento de "rescatar" una figura vilipendiada por múltiples autores, con el objeto aparente de aproximarse a un juicio más ponderado. Esta intención reivindicativa se manifiesta en 
la presentación de la novela que poco antes de su publicación hiciera el autor ante los integrantes del taller literario "Calicanto", de Caracas:

el Tirano Aguirre, a mi juicio, ha sido un personaje deformado por los historiadores, los novelistas, los cronistas que han escrito sobre él. ... Fueron ellos los que crearon el gran monstruo, el gran criminal del siglo XVI ... Estas grandes injusticias que se cometían contra el personaje, las facetas extraordinarias de su vida que ninguno de los historiadores ni de los cronistas señalaron fue lo que me llevó a estudiarlo (Otero Silva 1978: I).

Sin embargo, en tanto novela histórica, $L A P l$ no asume por supuesto (¿cómo podría hacerlo?) una posición neutral capaz de producir una visión "objetiva" de un personaje o un proceso. Precisamente por ser novela histórica ella constituye una relectura, una reinterpretación y una problematización incluso de la figura y su momento, pero siempre, inevitablemente, desde una perspectiva estético-ideológica particular no exenta de contradicciones ideológicas, como las mostradas por Beatriz Pastor (1993: 119-20) respecto a las actitudes y expresiones despectivas del protagonista hacia indios y negros.

Desde las luces y las sombras de su trayectoria biográfica ficcionalizada, disimulando $\mathrm{u}$ omitiendo incluso aspectos de su vida que le son menos favorables, emerge entonces finalmente una imagen positiva, atractiva, de un temprano luchador por la libertad de las provincias americanas que conviene y se articula adecuadamente con las propuestas del autor. Aguirre es elegido así por su potencialidad ideológica, por la "fuerza revolucionaria" que el escritor halla en su biografia (Otero Silva, 1978).

En efecto, desde el título mismo, clarinada de alabanza, el retrato de Aguirre va siendo dibujado como símbolo (aún bastante crudo, por supuesto) de los principios de igualdad, democracia y derechos populares que son consustanciales a la ficción oteriana. Más aun, hasta en su calidad de participante anticipado en ese proceso de revueltas y golpes de estado que se ubica en el origen de todas las repúblicas hispanoamericanas, hasta cuando aparece sobreviviendo con astucia a los vaivenes del poder y estableciéndose finalmente como caudillo; sin necesidad de dejar de lado sus rasgos negativos de obsesión y autoritarismo, Lope va creciendo ante los ojos del lector como estandarte de una proposición libertaria y tal vez utópica. Por ello, en la misma nota aludida hace un momento se le vincula con Simón Bolívar, ese "otro hijo de fieles vascongados" que no sólo comprendió la significación histórica positiva de Lope de Aguirre, sino que en cierta forma se convirtió en un continuador de su proyecto al devolver al Perú, desde Venezuela la bandera libertaria que el Tirano trajera desde el Cuzco (1980: 251-52).

Así pues, lo que una perspectiva general y distanciada de este corpus novelístico nos muestra al final de este trayecto es que por debajo de las transformaciones estéticas, entre las que se distingue el tránsito del ímpetu testimonial y el esfuerzo realista a la novela de personaje histórico y la explícita conciencia metaficcional, por debajo de las modificaciones de asunto o procedimiento que separan a los dos grandes ciclos novelescos que hemos venido describiendo y comparando hasta aquí, yace una permanente preocupación por la comprensión y transformación de la realidad venezolana y, más en el fondo aún, una inalterada propuesta humanista, libertaria, democrática de proyección mucho más amplia. 
En efecto, sin llegar a ser nunca paradigmas moralizantes, casi todos los protagonistas oterianos (de Vidal Rojas y Carmen Rosa Villena, a Lope de Aguirre, a Juan Bautista y hasta el mismo Jesús del revisitado Evangelio de la novela última) se levantan como símbolos vivientes de una propuesta ideológica perseverante, de una consistente dirección ética y humana, dentro de una trayectoria literaria de indudable validez estética.

\section{REFERENCIAS BIBLIOGRÁFICAS}

Ainsa, Fernando. "La opresión del espacio en Casas muertas". Imagen 57. Caracas, 1972: 4-5.

Araujo, Orlando. "Qué buscaba Miguel Otero Silva". Narrativa venezolana contemporánea (1972) Caracas: Monte Ávila Editores, 1988, 134-154.

Osorio Tejeda, Nelson. "Miguel Otero Silva". La Habana: Casa de las Américas. Otero Silva, Miguel. Agua y cauce. México: Editorial México Nuevo, 1937.

Fiebre. Caracas: Elite, 1939.

25 poemas. Caracas: Elite, 1942.

Casas muertas. Prólogo de Carlos Pacheco (1955) Caracas: Monte Ávila, colección El Dorado, 1991.

Elegía coral a Andrés Eloy Blanco. Caracas: Tipografía Vargas, 1958. Oficina $N^{\circ} 1$. Buenos Aires: Losada, 1961.

La mar que es el morir. Caracas: Arte, 1965.

Fiebre. Prólogo del autor. Caracas: Tiempo Nuevo, 1971.

La muerte de Honorio. 1968; Barcelona: Seix Barral, 1980a.

Cuando quiero llorar no lloro. Caracas: Tiempo Nuevo, 1970.

Poesía completa. Caracas: Monte Ávila, 1972a.

Un morrocoy en el cielo. Caracas: Tiempo Nuevo, 1972b.

"Prueba oral de un novelista". Transcripción de un diálogo sobre su narrativa.

Prosa completa. Caracas: Seix Barral Venezolana, 1976, 39-58. Obra humorística completa. Barcelona: Seix Barral, 1977.

"Cita con Miguel Otero. Lope de Aguirre, Príncipe de la Libertad". Hojas de

Calicanto 3 (1978): I-L.

Lope de Aguirre, Príncipe de la Libertad (1979) Barcelona: Seix Barral, 1980b. La piedra que era Cristo. Bogotá: La Oveja Negra, 1984.

Pastor, Beatriz. "Las metamorfosis de Lope de Aguirre". Estudios. Revista de Investigaciones Literarias, I/1. Caracas. Universidad Simón Bolívar, 1993, $107-$ 120.

Paz Castillo, Fernando. "Miguel Otero Silva, el poeta" y "La mar que es el morir". Miguel Otero Silva. Su obra literaria. Caracas: Dirección de Cultura de la Universidad Central de Venezuela, 1975, 7-17 y 73-76.

Suero, Efraín. Cercanía de Miguel Otero Silva. Caracas: Oficina Central de Información, 1978. 
